Article

\title{
Chrysanthemi Zawadskii var. Latilobum Attenuates Obesity-Induced Skeletal Muscle Atrophy via Regulation of PRMTs in Skeletal Muscle of Mice
}

\author{
Ahyoung Yoo ${ }^{1,2}$, Young Jin Jang ${ }^{1}$, Jiyun Ahn ${ }^{1,3}$, Chang Hwa Jung ${ }^{1,3}$, Hyo Deok Seo ${ }^{1}$ and \\ Tae Youl Ha $1,3, *$ (D) \\ 1 Division of Food Functionality Research, Korea Food Research Institute, Wanju-gun 55365, Korea; \\ 50026@kfri.re.kr (A.Y.); jyj616@kfri.re.kr (Y.J.J.); jyan@kfri.re.kr (J.A.); chjung@kfri.re.kr (C.H.J.); \\ hyo-deok.seo@kfri.re.kr (H.D.S.) \\ 2 Department of Food and Nutrition, Chungnam National University, Daejeon 34134, Korea \\ 3 Division of Food Biotechnology, University of Science and Technology, Daejeon 34113, Korea \\ * Correspondence: tyhap@kfri.re.kr; Tel.: +82-63-219-9054
}

Received: 4 March 2020; Accepted: 15 April 2020; Published: 17 April 2020

\begin{abstract}
As obesity promotes ectopic fat accumulation in skeletal muscle, resulting in impaired skeletal muscle and mitochondria function, it is associated with skeletal muscle loss and dysfunction. This study investigated whether Chrysanthemi zawadskii var. latilobum $(\mathrm{CZH})$ protected mice against obesity-induced skeletal muscle atrophy and the underlying molecular mechanisms. High-fat diet (HFD)-induced obese mice were orally administered either distilled water, low-dose CZH (125 mg/kg), or high-dose $\mathrm{CZH}(250 \mathrm{mg} / \mathrm{kg})$ for $8 \mathrm{w}$. CZH reduced obesity-induced increases in inflammatory cytokines levels and skeletal muscle atrophy, which is induced by expression of atrophic genes such as muscle RING-finger protein 1 and muscle atrophy F-box. CZH also improved muscle function according to treadmill running results and increased the muscle fiber size in skeletal muscle. Furthermore, $\mathrm{CZH}$ upregulated $\mathrm{mRNA}$ and protein levels of protein arginine methyltransferases (PRMT)1 and PRMT7, which subsequently attenuated mitochondrial dysfunction in the skeletal muscle of obese mice. We also observed that CZH significantly decreased PRMT6 mRNA and protein expression, which resulted in decreased muscle atrophy. These results suggest that $\mathrm{CZH}$ ameliorated obesity-induced skeletal muscle atrophy in mice via regulation of PRMTs in skeletal muscle.
\end{abstract}

Keywords: Chrysanthemi zawadskii var. latilobum; obesity-induced skeletal muscle atrophy; PRMTs; mitochondrial function

\section{Introduction}

Skeletal muscle atrophy is a debilitating condition associated with decreased protein synthesis and the accelerated degradation of muscle fibers [1]. Reduced protein synthesis leads to sharp decreases in skeletal muscle mass, which may result in falls and possible bone fractures [2]. Degradation of muscle fibers is followed by reduced muscle strength and loss of mitochondria in myocytes [3]. Recently, skeletal muscle loss and dysfunction (physical strength, mobility, and vitality) have been associated with obesity, referred to as sarcopenic obesity [4]. Obesity promotes inflammation in adipose tissue, increased lipolysis, and subsequent ectopic fat accumulation in skeletal muscles, which results in impaired skeletal muscles [5]. In addition, the skeletal muscle of obese humans exhibits decreased mitochondrial content and reduced function of fatty acid oxidation [6].

Several transcriptional regulators have been reported to regulate muscle atrophy. For instance, peroxisome proliferator activated receptor gamma coactivator $1 \alpha(\mathrm{PGC} 1 \alpha)$ is the prime regulator of mitochondrial content and oxidative metabolism and is important for maintaining muscle energy 
homeostasis. PGC1 $\alpha$ is also an important factor that opposes the effect of forkhead transcription factor3 (FOXO3), which regulates the transcription of muscle atrophy-related genes [7]. Interestingly, recent studies have shown that protein arginine methyltransferases (PRMTs) regulate PGC1 $\alpha$ and FOXO3. PRMT1 coactivates nuclear receptors and has been reported to induce PGC1 $\alpha$ function through the methylation of several arginine residues in the C-terminal region [8]. Meanwhile, PRMT7 regulates PGC1 $\alpha$ expression via the activation of p38 mitogen-activated protein kinase (p38MAPK), likely through arginine methylation [9]. On the other hand, PRMT6 activates FOXO3 and the ubiquitin-proteasome degradation pathway in skeletal muscle [10].

Chrysanthemi zawadskii var. latilobum (CZH) is a perennial herb from the family Asteraceae. CZH is widely distributed in Asia and Northeastern Europe and has been used as a tea and as a traditional medicine in Korea and China as a treatment for inflammatory diseases, gastroenteric troubles, and uterine diseases such as menstrual irregularity and infertility [11,12]. The pharmacological attributes of CZH include anti-inflammatory, anti-oxidant [13-15], and hepatoprotective [16] effects. Interestingly, anti-hyperglycemia [17] and anti-obesity [18] effects of CZH have also been reported. Based on these studies, we hypothesized that $\mathrm{CZH}$-induced changes in glucose and fatty acid metabolisms would attenuate muscle atrophy. Therefore, the current study was designed to investigate whether $\mathrm{CZH}$ affected obesity-induced skeletal muscle atrophy and to clarify the possible in vivo mechanism of $\mathrm{CZH}$ regulating PRMTs.

\section{Results}

\subsection{CZH Ameliorated Obesity-Induced Skeletal Muscle Accumulation of Fat and Metabolic Parameters in Obese Mice}

To investigate the effect of $\mathrm{CZH}$ on obesity-induced skeletal muscle atrophy, we measured muscle weight and skeletal muscle triglyceride (TG) content. Muscle weight was calculated as the sum weights of the tibialis anterior, gastrocnemius, quadriceps, and triceps muscles. High-fat diet (HFD)-fed mice had increased body weight and decreased muscle weight compared to those of the chow-fed control mice (Chow). The final body weight of $\mathrm{CZH}$ groups did not differ from that of the HFD group (Figure 1A). The CZH groups tended to have slightly increased muscle weight (Figure 1B) compared to the HFD group. Furthermore, obesity promoted ectopic fat accumulation in skeletal muscle. The HFD induced TG accumulation in skeletal muscle, but either 125 (125CZH) or $250 \mathrm{mg} / \mathrm{kg} \mathrm{CZH} \mathrm{(250CZH)}$ significantly reduced the HFD-induced TG accumulation in skeletal muscle (Figure 1C). As the skeletal muscle is the major site of insulin-stimulated glucose disposal [19], we measured serum glucose and insulin levels. The HFD-fed mice had more serum glucose and insulin levels than the chow-fed mice. However, CZH treatment reduced the HFD-induced increased levels of glucose and insulin (Figure 1D). Obesity results in increased circulating inflammatory mediators, leading to metabolic derangements within skeletal muscle [20]. The HFD-fed mice had increased levels in the serum and mRNA expression in skeletal muscle of inflammatory cytokines such as tumor necrosis factor-alpha (TNF $\alpha$ ), monocyte chemoattractant protein 1 (MCP1), and interleukin 1 beta (IL-1ß). CZH reduced the obesity-induced increased levels of the inflammatory cytokines in both the serum (Figure 1E) and skeletal muscle (Figure 1F). To examine the toxicity of $\mathrm{CZH}$, we measured serum alanine aminotransferase (ALT) and aspartate aminotransferase (AST) levels. The serum levels of these enzymes were significantly increased in HFD-fed mice relative to the levels in the control group. CZH treatment attenuated the HFD-induced increase in serum ALT and AST levels (Figure 1G). These results indicate that CZH ameliorated the obesity-induced fat accumulation and metabolic parameters in obese mice. 
A

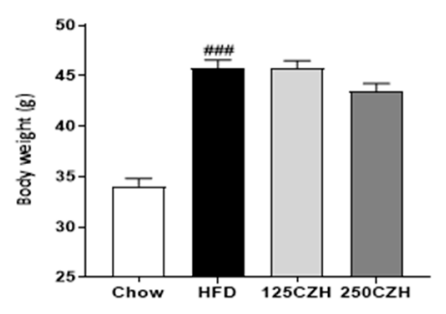

B

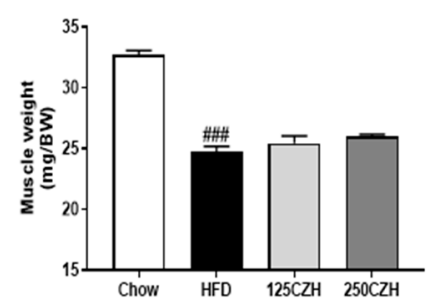

C

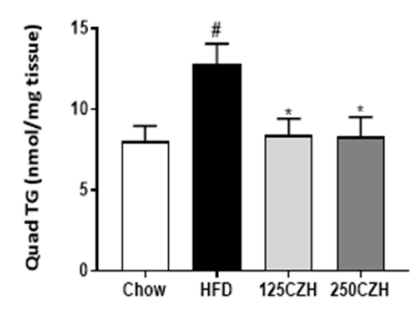

D
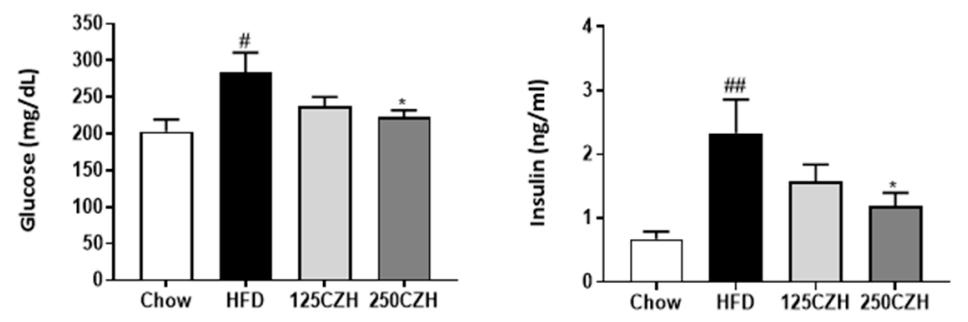

E
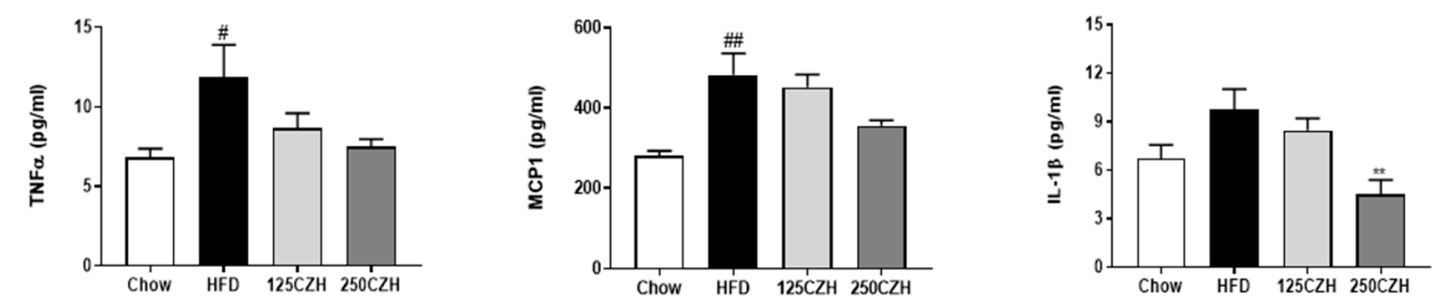

$\mathrm{F}$

G
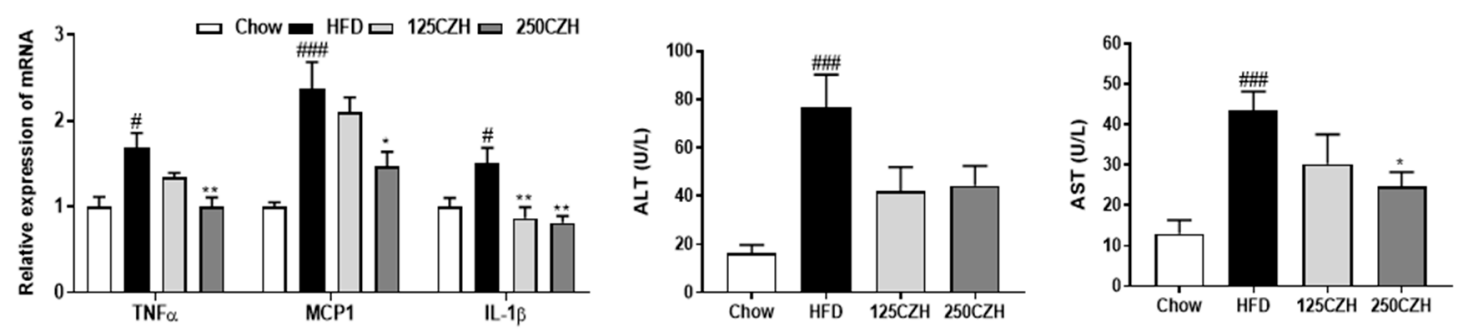

Figure 1. Effect of Chrysanthemi zawadskii var. latilobum (CZH) on obesity-induced skeletal muscle fat accumulation and metabolic parameters in C57BL/6 mice. Male C57BL/6 mice fed a high-fat diet (HFD) for $9 \mathrm{w}$ to induce obesity. The diet-induced obese mice were then maintained on an HFD and orally administered either distilled water (HFD), low-dose CZH (125 mg/kg; 125CZH), or high-dose CZH $(250 \mathrm{mg} / \mathrm{kg}$; $250 \mathrm{CZH})$ for $8 \mathrm{w}$. Age-matched mice were fed a standard chow diet (Chow) as a control group for comparison. (A) Body weights of the experimental mice. (B) Skeletal muscle weights of the experimental mice. (C) Triglyceride (TG) levels in quadriceps muscle of the experimental mice. The serum levels of (D) glucose, insulin, and (E) inflammatory cytokines, including TNF $\alpha, M C P 1$, and IL-1 $\beta$ in the experimental mice. (F) TNF $\alpha, M C P 1$, and IL-1 $\beta$ mRNA levels in the quadriceps muscle of the experimental mice were analyzed by qRT-PCR. (G) The serum alanine aminotransferase (ALT) and aspartate aminotransferase (AST) levels of the experimental mice. Results are expressed as mean $\pm \mathrm{SEM}$ $(n=8) .{ }^{*} p<0.05,{ }^{* *} p<0.01$ versus the HFD group. $\# p<0.05, \# \#<0.01$, \#\#\# $p<0.001$ versus the Chow-fed group.

\subsection{CZH Inhibited Obesity-Induced Skeletal Muscle Atrophy in HFD-Fed Mice}

Two muscle-specific E3 ubiquitin ligases, muscle RING-finger protein 1 (MuRF1) and muscle atrophy F-box (Atrogin), are key regulators of ubiquitin-mediated protein degradation in skeletal 
muscle. We evaluated the effect of CZH on MuRF1 and Atrogin gene expression in skeletal muscle. HFD increased MuRF1 and Atrogin mRNA and protein levels compared to those of the Chow mice. However, CZH significantly decreased MuRF1 and Atrogin mRNA expression (Figure 2A), which correlated with decreases in MuRF1 and Atrogin protein levels (Figure 2B). The combination of decreased physical activity (running) and increased weakness (grip strength) of the obese mice fulfilled the criteria for skeletal muscle atrophy. We then evaluated the effect of CZH on exercise performance using treadmill running and grip strength. HFD decreased the running distance, time to exhaustion, and grip strength compared to those of the Chow mice. However, $\mathrm{CZH}$ increased the running distance and time to exhaustion (Figure $2 \mathrm{C}$ ) and there was a trend toward increased grip strength in the $\mathrm{CZH}$ group (Figure 2D). These results indicate that $\mathrm{CZH}$ greatly improved the HFD-induced skeletal muscle atrophy in obese mice.
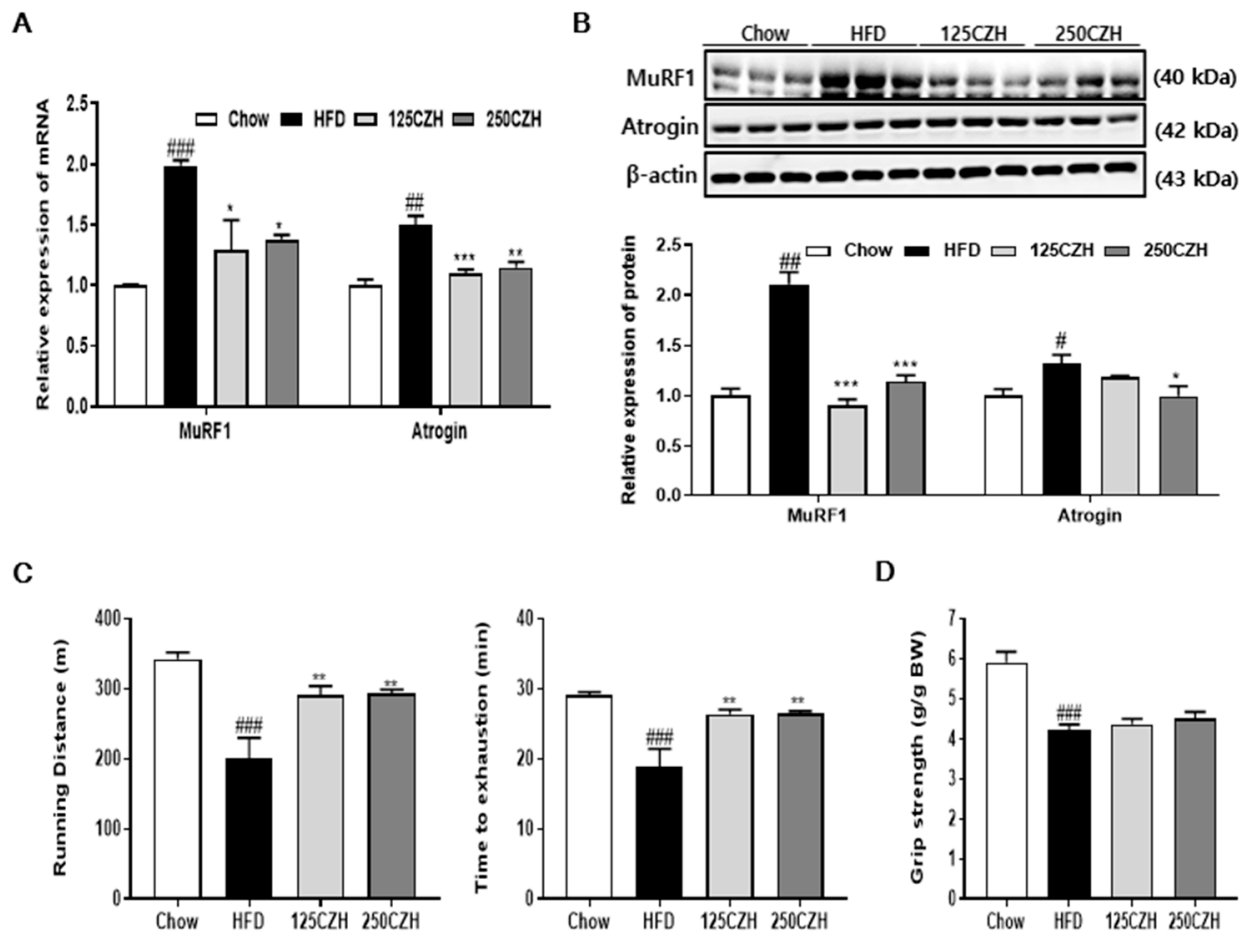

Figure 2. Effect of $\mathrm{CZH}$ on obesity-induced skeletal muscle atrophy in HFD-fed mice. (A) Expression levels of muscle atrophy-related genes muscle RING-finger protein 1 (MuRF1) and Atrogin in quadriceps muscle quantified by qRT-PCR. (B) Expression levels of MuRF1 and Atrogin in gastrocnemius muscle quantified by Western blotting. Band density was analyzed using ImageJ software. (C and D) Exercise capacity was measured according to running distance $(\mathrm{m})$, time (min), and grip strength (g/g BW). Results are expressed as mean $\pm \operatorname{SEM}(n=8) .{ }^{*} p<0.05,{ }^{* *} p<0.01,{ }^{* * *} p<0.001$ versus the HFD group. $\# p<0.05$, \#\# $p<0.01$, \#\#\# $p<0.001$ vs. the Chow-fed group.

\subsection{CZH Increased Muscle Fiber Size and Myosin Heavy Chain (MHC) Isoform in Obese Mice}

Muscle atrophy results in a decreased cross-sectional area (CSA) of skeletal muscle. According to muscle CSA measurements, feeding mice an HFD decreased muscle fiber size compared to that of the Chow mice. However, CZH increased the CSA of skeletal muscle compared to that of the HFD group (Figure 3A). To determine whether CZH altered muscle fiber type, mRNA and protein levels of MHC in skeletal muscle were quantified by qRT-PCR and Western blotting. As shown in Figure 3B,C, mRNA expressions of $\mathrm{MHC} 1$ and $\mathrm{MHC} 2 \mathrm{~A}$, respectively, in the $250 \mathrm{CZH}$ group were significantly increased compared to those of the HFD group. However, mRNA expression levels of MHC2B tended to increase (Figure 3B). Total MHC, MHC1, MHC2A, and MHC2B protein levels were significantly increased in skeletal muscle of the $250 \mathrm{CZH}$ group compared to those of the HFD group (Figure 3C). These results 
indicate that $\mathrm{CZH}$ increased the muscle fiber size and the amount of $\mathrm{MHC}$ muscle fiber isoform in HFD-fed mice.

A
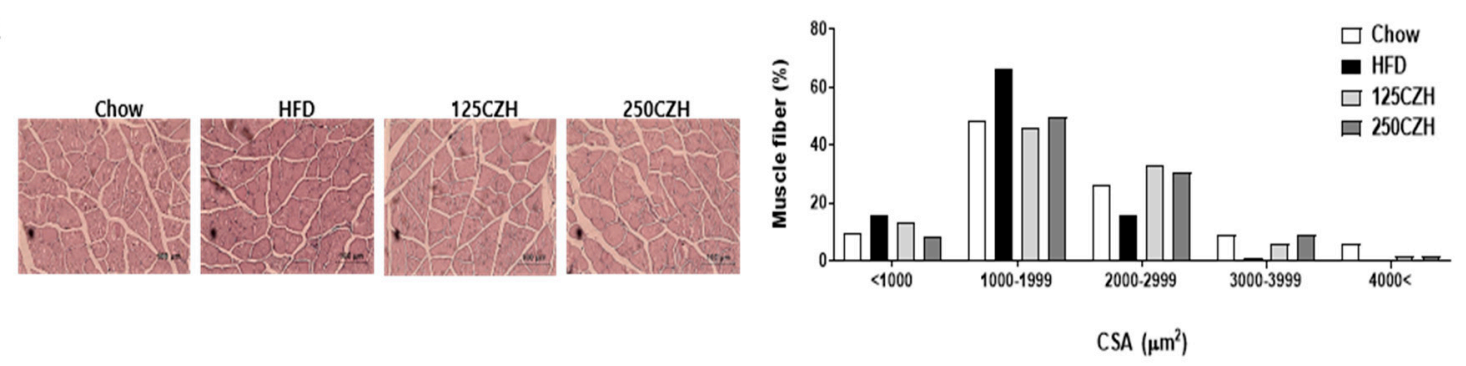

B

C
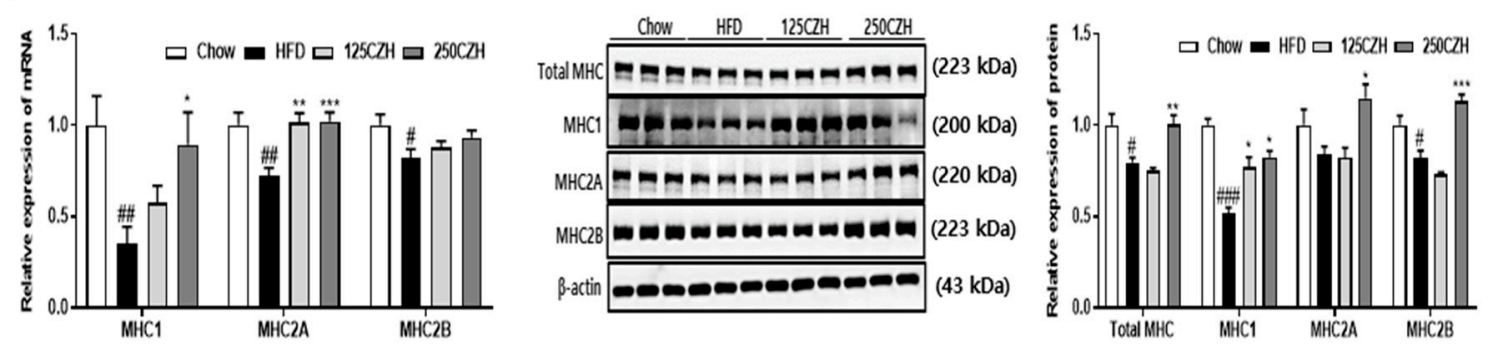

Figure 3. Effect of $\mathrm{CZH}$ on muscle fiber size and type in mice. (A) Representative image of myofiber cross-section of gastrocnemius muscle (hematoxylin and eosin staining; scale bar, $100 \mu \mathrm{m}$ ). Images were analyzed by light microscopy, and cross-sectional area (CSA) was measured. Distribution of muscle fiber CSA ( $n=3$ per group). (B) qRT-PCR analyses of MHC1, MHC2A, and MHC2B mRNA expression in quadriceps muscle. (C) Expression of total MHC, MHC1, MHC2A, and MHC2B in gastrocnemius muscle as determined by Western blotting. Band density was analyzed using ImageJ software (National Institutes of Health). Results are expressed as mean $\pm \operatorname{SEM}(n=8) .{ }^{*} p<0.05,{ }^{* *} p<0.01,{ }^{* * *} p<0.001$ versus the HFD group. \# $p<0.05$, \#\# $p<0.01$, \#\#\# $p<0.001$ vs. the Chow-fed group.

\subsection{CZH Regulated Skeletal Muscle PRMTs in Obese Mice}

PRMT1 and PRMT7 have been reported to play critical roles in PGC1 $\alpha$ function $[8,9]$, which increases mitochondrial biogenesis and fatty acid $\beta$-oxidation through methylation of several arginine residues. We observed that CZH supplementation increased PRMT1, PRMT7, and PGC1 $\alpha$ mRNA expression (Figure 4A), which translated into increased PRMT1, PRMT7, and PGC1 $\alpha$ protein levels (Figure 4B). We also examined the expression levels of nuclear respiratory factor 1 (NRF1), nuclear factor erythroid 2-related factor 2 (NRF2), kelch-like ECH-associated protein 1 (Keap1), mitochondrial transcription factor A (TFAM), estrogen-related receptor gamma (ERR $\gamma$ ), and PPAR $\delta$ in skeletal muscle, which are known to be regulated by PGC1 $\alpha$. Expression levels of NRF1, NRF2, and TFAM mRNAs were significantly elevated by CZH supplementation, and the expression of ERR $\gamma$, and PPAR $\delta$ mRNA tended to increase. However, the mRNA level of Keap1, a negative regulator of NRF2, was significantly reduced in the CZH-treated group relative to the levels in the HFD group (Figure 4C). CZH supplementation also enhanced the protein expression of NRF1, NRF2, ERR $\gamma$, and PPAR $\delta$ compared to those in HFD-fed mice (Figure 4D). PRMT6 activates FOXO3 and the ubiquitin-proteasome degradation pathway in skeletal muscle, resulting in muscle atrophy [10]. We observed that CZH significantly decreased PRMT6 mRNA levels and protein expression elevated by HFD (Figure 4E,F, respectively). Furthermore, levels of phospho-FOXO3 in skeletal muscle was reduced by $\mathrm{CZH}$ (Figure 4F). These results indicate that CZH regulated the skeletal muscle PRMTs in HFD-fed mice. 
A

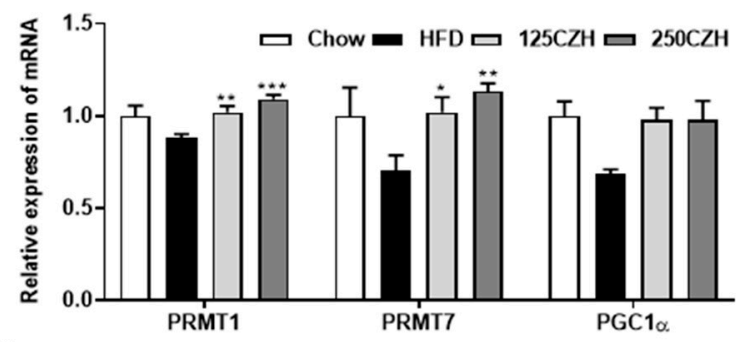

C

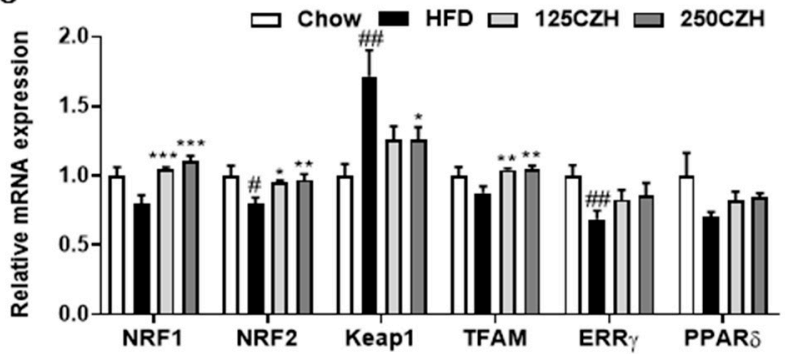

B

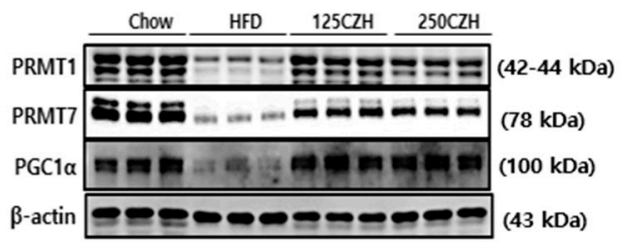

D

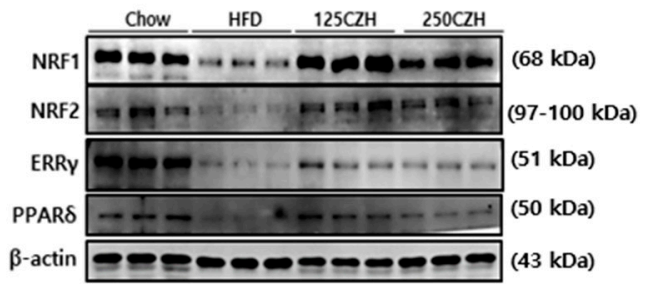

E

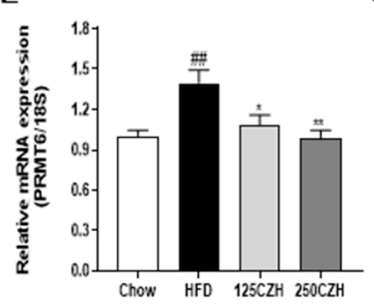

$\mathbf{F}$

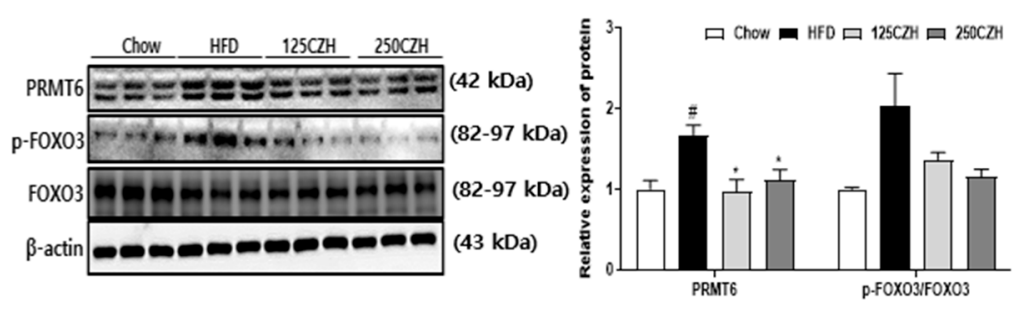

Figure 4. Effect of CZH on regulation of skeletal muscle PRMTs in mice. (A) Expression levels of PRMT1, PRMT7, and PGC1 $\alpha$ genes in quadriceps muscle quantified by qRT-PCR. (B) Expression levels of PRMT1, PRMT7, and PGC1 $\alpha$ genes in gastrocnemius muscle quantified by Western blotting. (C) qRT-PCR analyses of NRF1, NRF2, Keap1, TFAM, ERR $\gamma$, and PPAR $\delta$ mRNA expression in quadriceps muscle. (D) Expression of NRF1, NRF2, ERR $\gamma$, and PPAR $\delta$ in gastrocnemius muscle as determined by Western blotting. (E) PRMT6 mRNA levels in quadriceps muscle. (F) Expression of total PRMT6, p-FOXO3, and FOXO3 in gastrocnemius muscle as determined by Western blotting. Band density was analyzed using ImageJ software. Results are expressed as mean $\pm \operatorname{SEM}(n=8) .{ }^{*} p<0.05,{ }^{* *} p<0.01,{ }^{* * *} p<0.001$ versus the HFD group. \# $p<0.05$, \#\# $p<0.01$, \#\#\# $p<0.001$ versus the Chow-fed group.

\subsection{CZH Improved Mitochondrial Dysfunction in HFD-Fed Mice}

Several studies have shown that skeletal muscle from obese mice exhibits reduced citrate synthase activity and those of several complexes of the electron transport chain, as well as decreased oxygen consumption and ATP production [21-23]. To investigate the effect of $\mathrm{CZH}$ on mitochondrial function, we measured the mitochondrial DNA (mtDNA) content and the activities of citrate synthases and mitochondrial respiratory complexes I and II in the skeletal muscle. As shown in Figure 5A, the $\mathrm{CZH}$-treated mice tended to have more mtDNA content than HFD-fed mice. The citrate synthase and complex I and II subunit activities decreased significantly in the skeletal muscle of the HFD group. However, $\mathrm{CZH}$ improved citrate synthase and complex I and II subunit activities in the skeletal muscle (Figure 5B,C). We also analyzed mRNA levels of oxidative phosphorylation (OXPHOS) genes in skeletal muscle (Figure 5D). HFD-fed mice tended to have a decreased mRNA expression of OXPHOS genes in skeletal muscle. In contrast, the $\mathrm{CZH}$ groups tended to have an increased mRNA expression of OXPHOS genes in skeletal muscle compared to that of HFD-fed mice. Specifically, mRNA levels of the NADH:ubiquinone oxidoreductase subunit AB1 (NDUFAB1), cytochrome c (CYCS), ubiquinol-cytochrome $\mathrm{C}$ reductase core protein 1 (UQCRC1), and ubiquinol-cytochrome $\mathrm{C}$ reductase rieske iron-sulfur polypeptide 1 (UQCRFS1) complexes I and III in the muscle of the CZH group were 
significantly increased compared to those in the HFD-fed mice (Figure 5D). These results indicate that $\mathrm{CZH}$ increases mitochondrial oxidative capacity, leading to improvements in the mitochondrial dysfunction in HFD-fed mice.

A

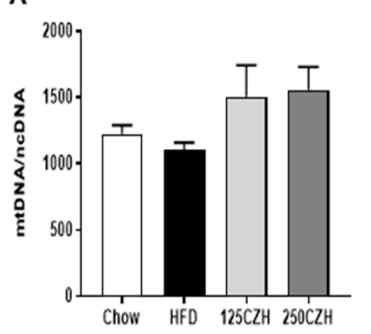

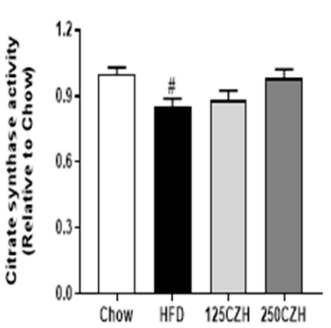
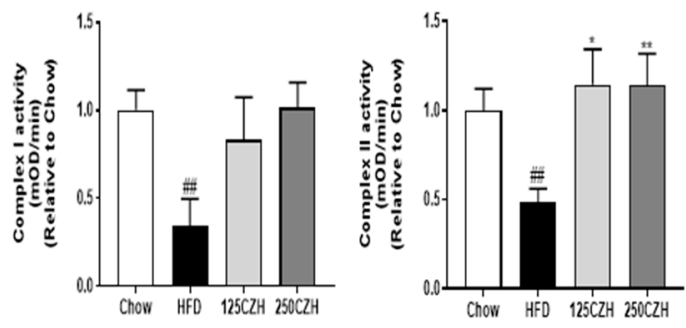

D

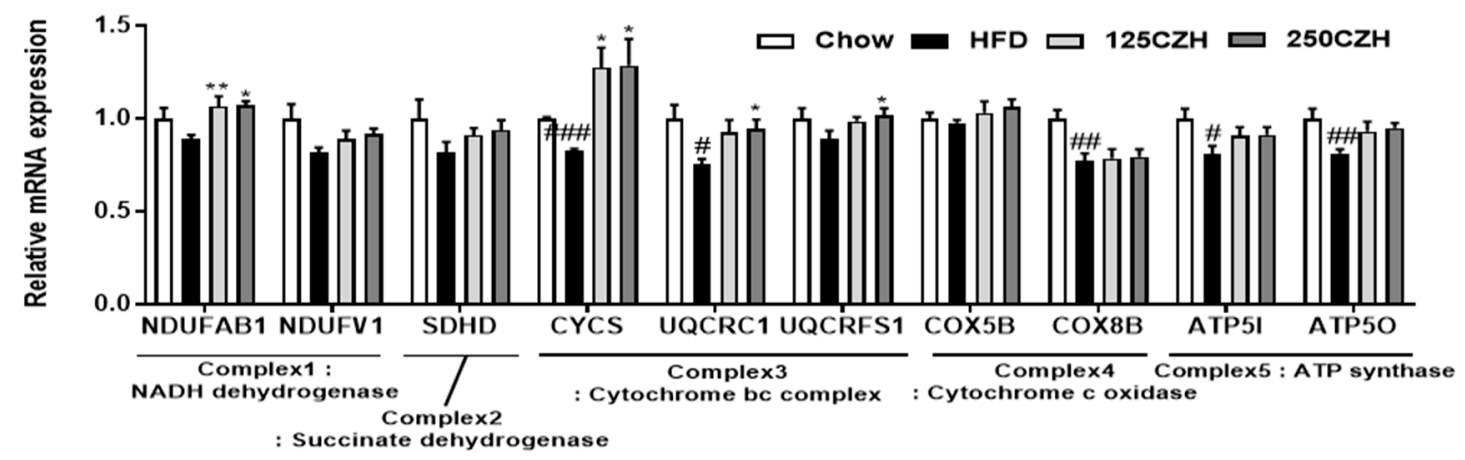

Figure 5. Effect of CZH on mitochondrial dysfunction in obese mice. (A) Mitochondrial DNA (mtDNA) content, (B) citrate synthase activity in quadriceps muscle of the mice. (C) Complex I and Complex II enzyme activities in gastrocnemius muscle of the mice. (D) Relative transcript levels in quadriceps muscle of genes encoding proteins involved in OXPHOS. Results are expressed as mean $\pm \operatorname{SEM}(n=8)$. ${ }^{*} p<0.05,{ }^{* *} p<0.01,{ }^{* * *} p<0.001$ versus the HFD group. $\# p<0.05$, \#\# $p<0.01$, \#\#\# $p<0.001$ vs. the Chow-fed group.

\subsection{CZH, Linarin, and Luteolin Attenuated Palmitic Acid-Induced Muscle Atrophy in C2C12 Cells}

To investigate which component(s) of $\mathrm{CZH}$ contributed to the protective effect of $\mathrm{CZH}$ on obesity-induced muscle atrophy, we examined the effect of linarin and luteolin, which have been reported to be the bioactive components of $\mathrm{CZH}$. Experiments were performed using palmitic acid (PA)-treated differentiated C2C12 myoblasts (myotubes) to model an environment similar to obesity. As shown in Figure 6, PA treatment of C2C12 cells increased the mRNA expression levels of MuRF1 and Atrogin genes compared to those of bovine serum albumin (BSA)-treated control cells. However, treatment with $\mathrm{CZH}$, linarin, and luteolin significantly decreased MuRF1 and Atrogin mRNA expression in $\mathrm{C} 2 \mathrm{C} 12$ cells. 
A

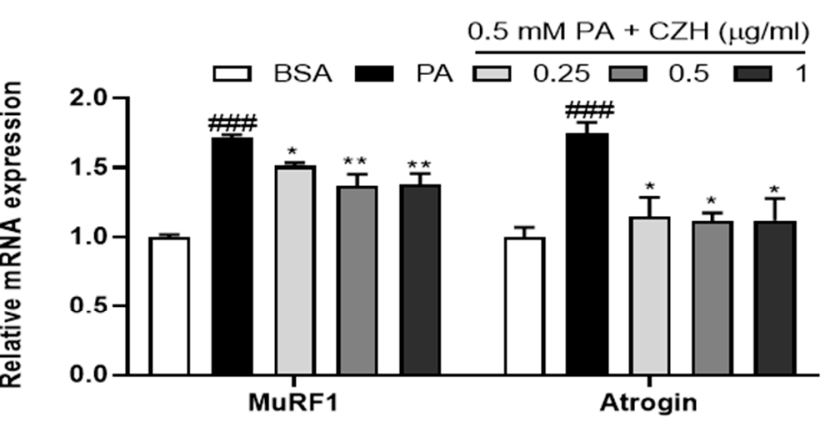

B

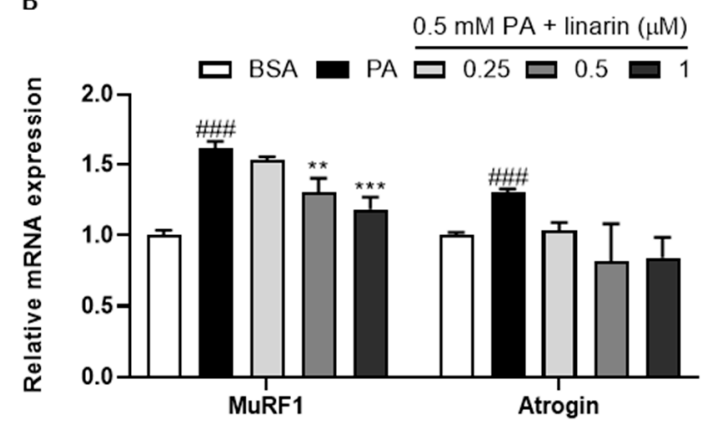

C

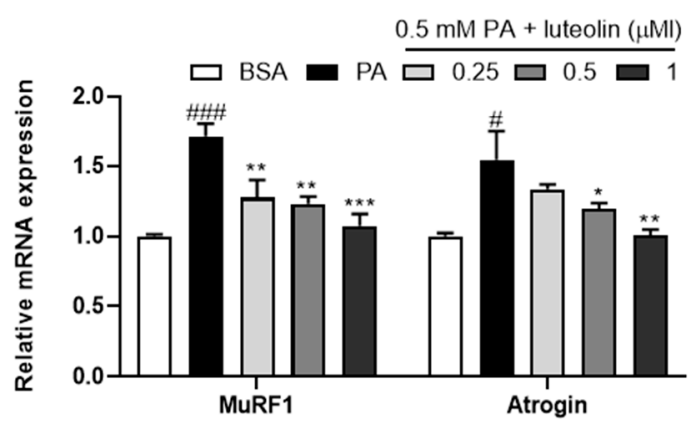

Figure 6. Effect of $\mathrm{CZH}$, linarin, and luteolin on palmitic acid (PA)-induced muscle atrophy in $\mathrm{C} 2 \mathrm{C} 12$ cells. The cells were treated with $0.5 \mathrm{mM}$ PA for $24 \mathrm{~h}$ in the presence or absence of $\mathrm{CZH}$, linarin, and luteolin on day 4 of differentiation. (A-C) Expression levels of muscle atrophy-related genes quantified by qRT-PCR for MuRF1 and Atrogin in PA-treated myotubes. Results are expressed as mean \pm SEM from three independent measurements. ${ }^{*} p<0.05,{ }^{* *} p<0.01,{ }^{* * *} p<0.001$ versus PA-treated myotubes. $\# p<0.05, \# \# p<0.01, \# \#$, $p<0.001$ vs. the BSA-treated myotubes.

\section{Discussion}

Sarcopenic obesity accompanied by combined abnormal muscle loss and the accumulation of body fat correlates with muscle strength and function and synergistically maximizes their health-threatening effects $[24,25]$. Recent studies suggest that diet-induced obesity alone may reprogram skeletal muscle to increase the production of inflammatory cytokines, including TNF $\alpha, M C P 1$, and IL-1 $\beta$ [26]. Elevated circulating TNF $\alpha$ in obese individuals can especially lead to muscle loss and inflammatory myopathies by regulating the activation and secretion of other inflammatory cytokines $[27,28]$. In the current study, HFD-induced obese mice exhibited increased levels of inflammatory cytokines levels and skeletal muscle atrophy, as indicated by the induction of atrophic genes MuRF1 and Atrogin and the reduction of skeletal muscle CSA. However, CZH groups demonstrated a reversal of the obesity-induced inflammation and skeletal muscle atrophy. Obesity is also known to further promote ectopic fat accumulation in skeletal muscle, but our findings showed that $\mathrm{CZH}$ significantly reduced TG accumulation in skeletal muscle.

Mitochondria are closely related to the function of the skeletal muscles, as these organelles constitute the main energy supply for contractile muscles [29]. For example, mitochondria are involved in cell death through the release of apoptogenic factors, which induce DNA condensation, DNA degradation, and apoptosome formation [30]. Elevated apoptosis in the skeletal muscle has been increasingly recognized to cause muscle atrophy [31]. Furthermore, mitochondria are a major source of cellular reactive oxygen species that emerge as superoxide molecules at various positions along the electron transport chain [32]. Oxidative stress has been suggested to be a key factor contributing to the initiation and progression of muscle atrophy [33].

The skeletal muscle of obese individuals characteristically shows lower mtDNA content and decreased citrate synthase activity [34,35]. Mitochondrial biogenesis is initiated with the increased 
transcription of both nuclear DNA and mtDNA [36]. PGC1 $\alpha$ regulates mitochondrial biogenesis through regulation of NRF1 and NRF2 [37], which, in turn, regulate TFAM [38]. TFAM plays an important role in maintaining the mtDNA copy number and structure and is, therefore, crucial for efficient transcription of mtDNA, which encodes the core hydrophobic proteins involved in OXPHOS [39]. PGC-1 $\alpha$ not only stimulates mitochondrial biogenesis through NRF1 and NRF2 expression, but also leads to activation of genes responsible for fatty acid oxidation through increased ERR $\gamma$ and PPAR $\delta$ expression. ERR $\gamma$, which is active even when PGC1 $\alpha$ is not induced, shares many target genes with ERR $\alpha$ [40]. When PGC1 is induced, ERR $\alpha$ is the primary regulator of the mitochondrial biogenic gene network [41]. To induced fatty acid oxidation, PPAR $\delta$ increases the proportion of oxidative fibers that are rich in mitochondria, thereby dramatically boosting mitochondrial oxidative metabolism. In the current study, HFD-induced obese mice exhibited decreased citrate synthase and mitochondrial respiratory complexes I and II activity in skeletal muscle. Furthermore, feeding mice an HFD decreased PGC1 $\alpha$ mRNA levels and protein expression in skeletal muscle. However, CZH reversed these reductions.

PGC1 $\alpha$ deficiency also leads to abnormal oxidative fiber growth and increased body fat [42]. Muscle fibers are categorized into two types, which include slow oxidative type 1 and fast glycolytic fiber type 2 [43]. Type 1 muscle fibers are primarily used for endurance exercise, while type 2 muscles are used for short explosive movements. We determined that $\mathrm{CZH}$ promoted endurance exercise and increased MHC1 and MHC2A mRNA and protein levels in skeletal muscle. Therefore, increased mitochondrial biogenesis and fatty acid oxidation in skeletal muscle alleviated obesity-induced skeletal muscle atrophy and resulted in improved endurance exercise performance.

PRMTs are a group of nine enzymes that catalyze the transfer of methyl groups to target protein [44]. Dysregulation of PRMT expression or PRMT activity is associated with many prevalent health disorders, including cancer and neurodegenerative and cardiovascular diseases [45]. Recent studies have begun to describe PRMT expression and function under conditions of metabolic dysfunction. For instance, PRMT7 expression in obese mice is reduced in skeletal muscle compared to that in their lean littermates, whereas whole body PRMT7 KO animals show exacerbated age-related obesity [9]. We found that CZH increased the expression of RRMT7 mRNA and protein in the skeletal muscle of obese mice. There are no previous reports on the role of PRMT1 and PRMT6 in obesity-induced skeletal muscle atrophy. However, recent studies have reported elevated PRMT1 activity following acute exercise in mice [46] and that skeletal muscle-specific PRMT KO mice display significant reduction in muscle mass [10]. These previous studies also provided strong evidence for a crucial role of PRMT1 in muscle atrophy by identifying the PRMT1-PRMT6-FOXO3 pathway [10]. Our results showed that HFD-induced obese mice exhibited a reduction in PRMT1 levels and an increase in PRMT6 levels. Furthermore, CZH reversed the expression of RRMT1 and RRMT6 in the skeletal muscle of obese mice.

CZH is a plant rich in flavonoids, especially linarin, luteolin, and acacetin $[12,47,48]$, which have a variety of pharmacological properties. Interestingly, our results showed that linarin and luteolin decreased mRNA levels of atrophic genes in PA-treated C2C12 cells. This was consistent with a previous report that luteolin inhibits the expression of MuRF1 and Atrogin at both the transcriptional and translational levels in skeletal muscle of a cancer-induced skeletal and cardiac muscle atrophy model [49]. Pretreatment with luteolin significantly prevents the decrease in C2C12 myotube diameter caused by LPS stimulation [50]. In a dexamethasone-induced skeletal muscle atrophy model, luteolin has a protective activity through its antioxidant and anti-apoptotic properties [51]. According to several studies, linarin makes up approximately $17 \%$ of the content of a $50 \%$ ethanol extract of CZH [52] and luteolin makes up approximately $0.5 \%$ of a methanol extract of $\mathrm{CZH}$ flowers [53]. Based on these results, the protective effect of $\mathrm{CZH}$ on PA-induced muscle atrophy may be due to synergistic effects of linarin and luteolin. Further research investigating the in vivo effects of these two main compounds of $\mathrm{CZH}$ is recommended. 


\section{Materials and Methods}

\subsection{Sample Preparation}

CZH was purchased from Jeonnam herbal medicine farmer's cooperative, Hwasun, South Korea. The dried CZH $(0.5 \mathrm{~kg})$ was soaked in $50 \%$ ethanol $(5 \mathrm{~L})$ at room temperature overnight. The ethanol extract was then filtered through No. 2 filter paper (Toyo Roshi Kaisha, Tokyo, Japan), concentrated under vacuum at $37^{\circ} \mathrm{C}$, and then freeze-dried. Finally, the freeze-dried $\mathrm{CZH}$ extracts were stored at $-20{ }^{\circ} \mathrm{C}$ until use.

\subsection{Animals}

All animal experiments were conducted in accordance with the Guidelines for Institutional Animal Care and Use Committee of the Korea Food Research Institute (KFRI-IACUC, KFRI-M-19013, approved 03/25/2019). Male C57BL/6 mice ( $4 \mathrm{w}$ old) were maintained at a constant temperature $\left(21-25{ }^{\circ} \mathrm{C}\right)$ and humidity (50\%-60\%) in an environment-controlled room with a $12 \mathrm{~h}$ light/12 h dark cycle and free access to food and water. To induce obesity, after $1 \mathrm{w}$ of adaptation, the mice were fed an HFD ad libitum for 9 w (D12451; Research Diets, New Brunswick, NJ, USA) consisting of 45\% calories as fat. Twenty-one HFD-induced obese mice were continued to be fed an HFD and were also orally administered either distilled water (HFD), low-dose CZH (125 mg/kg) dissolved in distilled water $(125 \mathrm{CZH})$, or high-dose $\mathrm{CZH}(250 \mathrm{mg} / \mathrm{kg})$ dissolved in distilled water $(250 \mathrm{CZH})$ for $8 \mathrm{w}$. As a control group to compare to the HFD-fed mice, age-matched mice were fed a standard chow diet (Chow). Body weight and food intake were measured weekly. At the end of the experiments, the mice were euthanized and blood was collected. Muscle tissues were immediately removed and the weights were measured. TG levels in quadriceps muscle were also analyzed using commercial kits (Abcam, Cambridge, MA, USA) following the manufacturer's instruction.

\subsection{Biochemical Analysis}

The blood was collected from the abdominal aorta into a blood collection tube. Serum was subsequently obtained by centrifuging the blood at $900 \times \mathrm{g}$ for $15 \mathrm{~min}$ at $4{ }^{\circ} \mathrm{C}$. Commercially available kits were used to assay the serum levels of the inflammatory cytokines TNF $\alpha, \mathrm{MCP} 1$ (Biolegend, San Diego, CA, USA), and IL-1 $\beta$ (Abcam). The serum levels of glucose (Embiel, Gyeonggi-do, South Korea), insulin (ALPCO Diagnostics, Salem, NH, USA), AST, and ALT (YD Diagnostics, Yongin, Korea) were measured by using commercial kits following the instructions of the manufacturers.

\subsection{Treadmill and Grip Strength Tests}

All mice were acclimated to running on a treadmill (Daemyoung Sci., Daejeon, Republic of Korea) for $2 \mathrm{~d}$. On the first day, the mice were exposed to the treadmill with a shock grid set at a $15^{\circ}$ incline and a speed of $5 \mathrm{~m} / \mathrm{min}$ for $10 \mathrm{~min}$ followed by a speed of $10 \mathrm{~m} / \mathrm{min}$ for $10 \mathrm{~min}$. On the second day, the mice were subjected to running at a $15^{\circ}$ incline for $5 \mathrm{~min}$ at a speed of $5 \mathrm{~m} / \mathrm{min}$ followed by $15 \mathrm{~min}$ at a speed of $10 \mathrm{~m} / \mathrm{min}$. Starting the following day after the $2 \mathrm{~d}$ of acclimation, the mice ran for $20 \mathrm{~min}$ at a $15^{\circ}$ incline and a speed of $10 \mathrm{~m} / \mathrm{min}$. The speed was increased by $2 \mathrm{~m} / \mathrm{min}$ every $2 \mathrm{~min}$. The endpoint of the speed increases was set when a mouse contacted the shock grid for $10 \mathrm{~s}$. Grip strength was measured five times using a grip strength test machine (Model GS3; Bioseb, Vitrolles, France) according to the manufacturer's instructions and the result was standardized according to body weight. The average grip strength values were calculated. The maximum and minimum values were not used.

\subsection{Histological and Immunohistochemical Analyses of Skeletal Muscle}

Fresh gastrocnemius muscle was fixed in $4 \%$ formaldehyde, embedded in paraffin, and $4 \mu \mathrm{m}$ sections were prepared. Gastrocnemius sections were stained with hematoxylin and eosin. Images were 
captured using an Olympus BX51 microscope and CSA was quantified using IMT iSolution DT 9.2 software (version 9.2, IMT i-Solution Inc., Vancouver, BC, Canada)

\subsection{Citrate Synthase and Mitochondrial Respiratory Complex I and II Activity}

To measure citrate synthase activity, homogenized quadriceps muscle tissues were centrifuged and measurements were performed using a Citrate Synthase Assay Kit (Sigma-Aldrich, St. Louis, MO, USA). The mitochondria were prepared using a Mitochondria Isolation Kit (Thermo Scientific, Rockford, IL, USA). Mitochondrial Complex I and II activity were measured in the gastrocnemius muscle tissues using a Complex I, II Enzyme Activity Microplate Assay Kit (Abcam).

\subsection{Cell Culture}

C2C12 myoblast cells (CRL-1772; ATCC, Manassas, VA, USA) were cultured in Dulbecco's Modified Eagle Medium (DMEM) supplemented with 10\% fetal bovine serum, $100 \mathrm{U} / \mathrm{mL}$ penicillin, and $100 \mu \mathrm{g} / \mathrm{mL}$ streptomycin at $37^{\circ} \mathrm{C}$ in a humidified $5 \% \mathrm{CO}_{2}$ atmosphere. For differentiation, the C2C12 cells were cultured in DMEM with $2 \%$ horse serum, $100 \mathrm{U} / \mathrm{mL}$ penicillin, and $100 \mu \mathrm{g} / \mathrm{mL}$ streptomycin for $4 \mathrm{~d}$. Samples of $\mathrm{CZH}$, linarin, and luteolin were treated for $24 \mathrm{~h}$ with $0.5 \mathrm{mM}$ PA on day 4 of differentiation. PA stock solutions were prepared by conjugating PA to fatty acid-free BSA as previously described (7\% BSA:5 mM PA; 5:1 molar ratio) [54]. A 7\% BSA stock solution was prepared as a control.

\subsection{Western Blot Analysis}

Protein from the gastrocnemius muscle was extracted using radioimmunoprecipitation assay (RIPA) buffer. Protein concentrations of the supernatants were determined using a Pierce BCA Protein Assay Kit (Thermo Scientific, Rockford, IL, USA) and BSA as the standard. Total protein (10 $\mu \mathrm{g}$ per lane) was separated by $10 \%$ SDS-polyacrylamide gel electrophoresis and transferred to polyvinylidene difluoride membranes (Bio-Rad, Hercules, CA, USA). The membranes were blocked for $1 \mathrm{~h}$ at room temperature with tris-buffered saline containing 5\% skim milk and $0.1 \%$ Tween 20 (Junsei, Tokyo, Japan). After overnight incubation at $4{ }^{\circ} \mathrm{C}$ with primary antibodies, the membranes were washed and incubated with a horseradish peroxidase-conjugated secondary antibody for $1 \mathrm{~h}$ at room temperature. Immunodetection was carried out with ECL Detection Reagent (Bio-Rad). All figures showing results of quantitative analysis using Image J software (National Institutes of Health, Bethesda, MD, USA) include data from at least three independent experiments.

\subsection{Quantitative Real-Time PCR}

Total RNA extraction from the quadriceps muscle and C2C12 cells were performed using a Qiagen RNeasy Fibrous Tissue Mini Kit (Qiagen Inc., Hilden, Germany) and NucleoSpin RNA (Macherey-Nagel, Duren, Germany), respectively. Complementary DNA (cDNA) using total RNA as the template was synthesized used a ReverTra Ace ${ }^{\circledR}$ Quantitative Reverse Transcription Polymerase Chain Reaction (qPCR RT) Master Kit (Toyobo Co., Ltd., Osaka, Japan) according to the protocol provided by the manufacturer. Quantitative PCR was performed using SYBR Green Real-Time PCR Master Mix (Toyobo Co., Ltd., Osaka, Japan) and a ViiA7 PCR system (Applied Biosystems, Foster City, $\mathrm{CA}, \mathrm{USA})$. The cDNA was used as a template in $20 \mu \mathrm{L}$ reaction mixtures that were processed using an initial step of $95^{\circ} \mathrm{C}$ for $5 \mathrm{~min}$, followed by 40 amplification cycles including $95^{\circ} \mathrm{C}$ for $5 \mathrm{~s} ; 55^{\circ} \mathrm{C}$ for $10 \mathrm{~s}$; and $72{ }^{\circ} \mathrm{C}$ for $15 \mathrm{~s}$. The amount of each mRNA was normalized to $18 \mathrm{~s}$ rRNA.

\subsection{0. mtDNA Content Quantitation}

Total DNA was extracted using the AccuPrep Genomic DNA Extraction Kit (Bioneer, Daejeon, Korea), and qPCR was performed using mtDNA- or ncDNA-specific primers [55]. 


\subsection{Statistical Analysis}

Data are expressed as the mean \pm SEM. Statistical analyses were performed using GraphPad Prism, version 7.04 software (GraphPad Software, San Diego, CA, USA). An unpaired $t$-test was used to assess differences between two groups (animals on standard Chow vs. HFD). One-way ANOVA was used to compare more than two groups followed by Dunnett's multiple comparison test (HFD, $125 \mathrm{CZH}$, and $250 \mathrm{CZH})$.

\section{Conclusions}

We showed that CZH ameliorated obesity-induced skeletal muscle atrophy in HFD-fed mice. This beneficial effect involved the regulation of PRMT1, PRMT6, and PRMT7, and the attenuation of the mitochondrial dysfunction. These results suggest that $\mathrm{CZH}$ may have a beneficial effect on the prevention and treatment of skeletal muscle atrophy in obesity. However, further clinical studies need to be carried out to confirm our findings in humans, and the results of this research will provide a basis for these clinical trials. In addition, further studies using healthy mice and aged mice are also recommended to have a better understanding of the effect of $\mathrm{CZH}$ on skeletal muscle atrophy.

Author Contributions: Conceptualization, T.Y.H. Data duration, C.H.J., Y.J.J. and J.A.; formal analysis, A.Y. and H.D.S.; Funding acquisition, T.Y.H. and J.A.; investigation, A.Y. and T.Y.H.; Supervision, T.Y.H.; writing一original draft preparation, A.Y.; writing - review and editing, T.Y.H. All authors have read and agreed to the published version of the manuscript.

Funding: This research was supported by the Main Research Program (E0160500-04) of the Korea Food Research Institute funded by Ministry of Science and ICT.

Conflicts of Interest: The authors declare that there are no conflicts of interest.

\section{Abbreviations}

$\begin{array}{ll}\text { PPAR } & \text { peroxisome proliferator activated receptor } \\ \text { PGC1 } \alpha & \text { PPAR gamma coactivator 1 } \alpha \\ \text { FOXO3 } & \text { forkhead transcription factor3 } \\ \text { PRMT } & \text { protein arginine methyltransferase } \\ \text { CZH } & \text { Chrysanthemi zawadskii var. latilobum } \\ \text { TG } & \text { triglyceride } \\ \text { HFD } & \text { high-fat diet } \\ \text { TNF } \alpha & \text { tumor necrosis factor-alpha } \\ \text { MCP1 } & \text { monocyte chemoattractant protein 1 } \\ \text { IL-1 } 3 & \text { interleukin 1 beta } \\ \text { ALT } & \text { alanine aminotransferase } \\ \text { AST } & \text { aspartate aminotransferase } \\ \text { MuRF1 } & \text { muscle RING-finger protein 1 } \\ \text { Atrogin } & \text { muscle atrophy F-box } \\ \text { MHC } & \text { myosin heavy chain } \\ \text { CSA } & \text { cross-sectional area } \\ \text { NRF1 } & \text { nuclear respiratory factor 1 } \\ \text { NRF2 } & \text { nuclear factor erythroid 2-related factor 2 } \\ \text { Keap1 } & \text { kelch-like ECH-associated protein 1 } \\ \text { TFAM } & \text { mitochondrial transcription factor A } \\ \text { ERR } \gamma & \text { estrogen-related receptor gamma } \\ \text { mtDNA } & \text { mitochondrial DNA } \\ \text { OXPHOS } & \text { oxidative phosphorylation } \\ \text { PA } & \text { palmitic acid } \\ \text { BSA } & \text { bovine serum albumin } \\ \text { DMEM } & \text { Dulbecco's Modified Eagle Medium } \\ & \end{array}$




\section{References}

1. Foletta, V.C.; White, L.J.; Larsen, A.E.; Léger, B.; Russell, A.P. The role and regulation of MAFbx/atrogin-1 and MuRF1 in skeletal muscle atrophy. Pflügers Archiv Eur. J. Physiol. 2011, 461, 325-335. [CrossRef] [PubMed]

2. Cohen, S.; Nathan, J.A.; Goldberg, A.L. Muscle wasting in disease: Molecular mechanisms and promising therapies. Nat. Rev. Drug Discov. 2015, 14, 58. [CrossRef] [PubMed]

3. Roy, B.; Curtis, M.E.; Fears, L.S.; Nahashon, S.N.; Fentress, H.M. Molecular mechanisms of obesity-induced osteoporosis and muscle atrophy. Front. Physiol. 2016, 7, 439. [CrossRef] [PubMed]

4. Prado, C.; Wells, J.; Smith, S.; Stephan, B.; Siervo, M. Sarcopenic obesity: A critical appraisal of the current evidence. Clin. Nutr. 2012, 31, 583-601. [CrossRef]

5. Kraakman, M.J.; Murphy, A.J.; Jandeleit-Dahm, K.; Kammoun, H.L. Macrophage polarization in obesity and type 2 diabetes: Weighing down our understanding of macrophage function? Front. Immunol. 2014, 5, 470. [CrossRef]

6. Kim, J.-Y.; Hickner, R.C.; Cortright, R.L.; Dohm, G.L.; Houmard, J.A. Lipid oxidation is reduced in obese human skeletal muscle. Am. J. Physiol. Endocrinol. Metab. 2000, 279, E1039-E1044. [CrossRef]

7. Sandri, M.; Lin, J.; Handschin, C.; Yang, W.; Arany, Z.P.; Lecker, S.H.; Goldberg, A.L.; Spiegelman, B.M. PGC-1 $\alpha$ protects skeletal muscle from atrophy by suppressing FoxO3 action and atrophy-specific gene transcription. Proc. Natl. Acad. Sci. USA 2006, 103, 16260-16265. [CrossRef]

8. Kupr, B.; Handschin, C. Complex coordination of cell plasticity by a PGC- $1 \alpha$-controlled transcriptional network in skeletal muscle. Front. Physiol. 2015, 6, 325. [CrossRef]

9. Jeong, H.-J.; Lee, H.-J.; Vuong, T.A.; Choi, K.-S.; Choi, D.; Koo, S.-H.; Cho, S.C.; Cho, H.; Kang, J.-S. Prmt7 deficiency causes reduced skeletal muscle oxidative metabolism and age-related obesity. Diabetes 2016, 65, 1868-1882. [CrossRef]

10. Choi, S.; Jeong, H.-J.; Kim, H.; Choi, D.; Cho, S.-C.; Seong, J.K.; Koo, S.-H.; Kang, J.-S. Skeletal muscle-specific Prmt1 deletion causes muscle atrophy via deregulation of the PRMT6-FOXO3 axis. Autophagy 2019, 15, 1069-1081. [CrossRef]

11. Woo, K.-S.; Yu, J.-S.; Hwang, I.-G.; Lee, Y.-R.; Lee, C.-H.; Yoon, H.-S.; Lee, J.-S.; Jeong, H.-S. Antioxidative activity of volatile compounds in flower of Chrysanthemum indicum, C. morifolium, and C. zawadskii. J. Korean Soc. Food Sci. Nutr. 2008, 37, 805-809. [CrossRef]

12. Kwon, H.S.; Ha, T.J.; Hwang, S.W.; Jin, Y.M.; Nam, S.H.; Park, K.H.; Yang, M.S. Cytotoxic flavonoids from the whole plants of Chrysanthemum zawadskii Herbich var. latilobum Kitamura. Korean Soc. Life Sci. 2006, 16, 746-749.

13. He, J.; Chen, F.; Chen, S.; Lv, G.; Deng, Y.; Fang, W.; Liu, Z.; Guan, Z.; He, C. Chrysanthemum leaf epidermal surface morphology and antioxidant and defense enzyme activity in response to aphid infestation. J. Plant Physiol. 2011, 168, 687-693. [CrossRef] [PubMed]

14. Liu, Q.; Liu, H.; Yuan, Z.; Wei, D.; Ye, Y. Evaluation of antioxidant activity of chrysanthemum extracts and tea beverages by gold nanoparticles-based assay. Colloids Surf. B Biointerfaces 2012, 92, 348-352. [CrossRef] [PubMed]

15. Sung, N.-Y.; Park, Y.-Y.; Kim, Y.-E.; Cho, E.-J.; Kim, M.-H.; Ryu, G.-H.; Byun, E.-H.; Park, Y.-J. Immuno-Modulatory Activities of Polysaccharides separated from Chrysanthemum zawadskii var. latilobum in Macrophage Cells. Korean J. Food Nutr. 2016, 29, 431-437. [CrossRef]

16. Seo, J.Y.; Lim, S.S.; Park, J.; Lim, J.-S.; Kim, H.J.; Kang, H.J.; Park, Y.; Han, J.; Kim, J.-S. Protection by Chrysanthemum zawadskii extract from liver damage of mice caused by carbon tetrachloride is maybe mediated by modulation of QR activity. Nutr. Res. Pract. 2010, 4, 93-98. [CrossRef]

17. Kim, Y.-J.; Kim, H.-K.; Lee, H.S. Hypoglycemic effect of standardized Chrysanthemum zawadskii ethanol extract in high-fat diet/streptozotocin-induced diabetic mice and rats. Food Sci. Biotechnol. 2018, 27, 1771-1779. [CrossRef]

18. Park, J.A.; Jin, K.-S.; Kwon, H.J.; Kim, B.W. Antiobesity activity of Chrysanthemum zawadskii methanol extract. J. Life Sci. 2015, 25, 299-306. [CrossRef]

19. DeFronzo, R.A.; Jacot, E.; Jequier, E.; Maeder, E.; Wahren, J.; Felber, J. The effect of insulin on the disposal of intravenous glucose: Results from indirect calorimetry and hepatic and femoral venous catheterization. Diabetes 1981, 30, 1000-1007. [CrossRef] 
20. Sinha, I.; Sakthivel, D.; Varon, D.E. Systemic regulators of skeletal muscle regeneration in obesity. Front. Endocrinol. 2017, 8, 29. [CrossRef]

21. Lettieri-Barbato, D.; Cannata, S.M.; Casagrande, V.; Ciriolo, M.R.; Aquilano, K. Time-controlled fasting prevents aging-like mitochondrial changes induced by persistent dietary fat overload in skeletal muscle. PLoS ONE 2018, 13, e0195912. [CrossRef] [PubMed]

22. Choi, W.H.; Son, H.J.; Jang, Y.J.; Ahn, J.; Jung, C.H.; Ha, T.Y. Apigenin Ameliorates the Obesity-Induced Skeletal Muscle Atrophy by Attenuating Mitochondrial Dysfunction in the Muscle of Obese Mice. Mol. Nutr. Food Res. 2017, 61, 1700218. [CrossRef] [PubMed]

23. Sparks, L.M.; Xie, H.; Koza, R.A.; Mynatt, R.; Hulver, M.W.; Bray, G.A.; Smith, S.R. A high-fat diet coordinately downregulates genes required for mitochondrial oxidative phosphorylation in skeletal muscle. Diabetes 2005, 54, 1926-1933. [CrossRef] [PubMed]

24. Lee, J.; Hong, Y.-p.; Shin, H.J.; Lee, W. Associations of sarcopenia and sarcopenic obesity with metabolic syndrome considering both muscle mass and muscle strength. J. Prev. Med. Public Health 2016, 49, 35-44. [CrossRef]

25. Stenholm, S.; Harris, T.B.; Rantanen, T.; Visser, M.; Kritchevsky, S.B.; Ferrucci, L. Sarcopenic obesity-definition, etiology and consequences. Curr. Opin. Clin. Nutr. Metab. Care 2008, 11, 693-700. [CrossRef]

26. Ceddia, R.P.; Lee, D.; Maulis, M.F.; Carboneau, B.A.; Threadgill, D.W.; Poffenberger, G.; Milne, G.; Boyd, K.L.; Powers, A.C.; McGuinness, O.P. The PGE2 EP3 receptor regulates diet-induced adiposity in male mice. Endocrinology 2016, 157, 220-232. [CrossRef]

27. Chen, S.-E.; Jin, B.; Li, Y.-P. TNF- $\alpha$ regulates myogenesis and muscle regeneration by activating p38 MAPK. Am. J. Physiol. Cell Physiol. 2007, 292, C1660-C1671. [CrossRef]

28. Loell, I.; Lundberg, I. Can muscle regeneration fail in chronic inflammation: A weakness in inflammatory myopathies? J. Intern. Med. 2011, 269, 243-257. [CrossRef]

29. Chabi, B.; Ljubicic, V.; Menzies, K.J.; Huang, J.H.; Saleem, A.; Hood, D.A. Mitochondrial function and apoptotic susceptibility in aging skeletal muscle. Aging Cell 2008, 7, 2-12. [CrossRef]

30. Van Gurp, M.; Festjens, N.; Van Loo, G.; Saelens, X.; Vandenabeele, P. Mitochondrial intermembrane proteins in cell death. Biochem. Biophys. Res. Commun. 2003, 304, 487-497. [CrossRef]

31. Marzetti, E.; Hwang, J.C.; Lees, H.A.; Wohlgemuth, S.E.; Dupont-Versteegden, E.E.; Carter, C.S.; Bernabei, R.; Leeuwenburgh, C. Mitochondrial death effectors: Relevance to sarcopenia and disuse muscle atrophy. Biochim. Biophys. Acta (BBA) Gen. Subj. 2010, 1800, 235-244. [CrossRef] [PubMed]

32. Balaban, R.S.; Nemoto, S.; Finkel, T. Mitochondria, oxidants, and aging. Cell 2005, 120, 483-495. [CrossRef] [PubMed]

33. Jackson, M.J. Interactions between reactive oxygen species generated by contractile activity and aging in skeletal muscle? Antioxid. Redox Signal. 2013, 19, 804-812. [CrossRef] [PubMed]

34. Ritov, V.B.; Menshikova, E.V.; He, J.; Ferrell, R.E.; Goodpaster, B.H.; Kelley, D.E. Deficiency of subsarcolemmal mitochondria in obesity and type 2 diabetes. Diabetes 2005, 54, 8-14. [CrossRef] [PubMed]

35. Kelley, D.E.; He, J.; Menshikova, E.V.; Ritov, V.B. Dysfunction of mitochondria in human skeletal muscle in type 2 diabetes. Diabetes 2002, 51, 2944-2950. [CrossRef]

36. Gleyzer, N.; Vercauteren, K.; Scarpulla, R.C. Control of mitochondrial transcription specificity factors (TFB1M and TFB2M) by nuclear respiratory factors (NRF-1 and NRF-2) and PGC-1 family coactivators. Mol. Cell. Biol. 2005, 25, 1354-1366. [CrossRef]

37. Ventura-Clapier, R.; Garnier, A.; Veksler, V. Transcriptional control of mitochondrial biogenesis: The central role of PGC-1 $\alpha$. Cardiovasc. Res. 2008, 79, 208-217. [CrossRef]

38. Virbasius, J.V.; Scarpulla, R.C. Activation of the human mitochondrial transcription factor A gene by nuclear respiratory factors: A potential regulatory link between nuclear and mitochondrial gene expression in organelle biogenesis. Proc. Natl. Acad. Sci. USA 1994, 91, 1309-1313. [CrossRef]

39. Kaufman, B.A.; Durisic, N.; Mativetsky, J.M.; Costantino, S.; Hancock, M.A.; Grutter, P.; Shoubridge, E.A. The mitochondrial transcription factor TFAM coordinates the assembly of multiple DNA molecules into nucleoid-like structures. Mol. Biol. Cell 2007, 18, 3225-3236. [CrossRef]

40. Dufour, C.R.; Wilson, B.J.; Huss, J.M.; Kelly, D.P.; Alaynick, W.A.; Downes, M.; Evans, R.M.; Blanchette, M.; Giguere, V. Genome-wide orchestration of cardiac functions by the orphan nuclear receptors ERR $\alpha$ and $\gamma$. Cell Metab. 2007, 5, 345-356. [CrossRef] 
41. Fan, W.; Evans, R. PPARs and ERRs: Molecular mediators of mitochondrial metabolism. Curr. Opin. Cell Biol. 2015, 33, 49-54. [CrossRef] [PubMed]

42. Leone, T.C.; Lehman, J.J.; Finck, B.N.; Schaeffer, P.J.; Wende, A.R.; Boudina, S.; Courtois, M.; Wozniak, D.F.; Sambandam, N.; Bernal-Mizrachi, C. PGC-1 $\alpha$ deficiency causes multi-system energy metabolic derangements: Muscle dysfunction, abnormal weight control and hepatic steatosis. PLoS Biol. 2005, 3, e101. [CrossRef] [PubMed]

43. Exeter, D.; Connell, D.A. Skeletal muscle: Functional anatomy and pathophysiology. Semin. Musculoskelet. Radiol. 2010, 14, 097-105. [CrossRef] [PubMed]

44. Bedford, M.T.; Clarke, S.G. Protein arginine methylation in mammals: Who, what, and why. Mol. Cell 2009, 33, 1-13. [CrossRef] [PubMed]

45. Blanc, R.S.; Richard, S. Arginine methylation: The coming of age. Mol. Cell 2017, 65, 8-24. [CrossRef]

46. Vanlieshout, T.L.; Stouth, D.W.; Tajik, T.; Ljubicic, V. Exercise-induced Protein Arginine Methyltransferase Expression in Skeletal Muscle. Med. Sci. Sports Exerc. 2018, 50, 447-457. [CrossRef]

47. Lee, Y. Studies on the constituents of Chrysanthemum sibiricum Fischer. Korean J. Pharm. Soc. 1967, 11, 7-16.

48. Han, S.; Sung, K.-h.; Yim, D.; Lee, S.; Lee, C.-k.; Ha, N.-j.; Kim, K. The effect of linarin on lps-lnduced cytokine production and nitric oxide inhibition in murine macrophages cell line RAW264. 7. Arch. Pharmacal Res. 2002, 25, 170-177. [CrossRef]

49. Chen, T.; Li, B.; Xu, Y.; Meng, S.; Wang, Y.; Jiang, Y. Luteolin reduces cancer-induced skeletal and cardiac muscle atrophy in a Lewis lung cancer mouse model. Oncol. Rep. 2018, 40, 1129-1137. [CrossRef]

50. Shiota, C.; Abe, T.; Kawai, N.; Ohno, A.; Teshima-Kondo, S.; Mori, H.; Terao, J.; TANAkA, E.; NIkAWA, T. Flavones inhibit LPS-induced atrogin-1/MAFbx expression in mouse C2C12 skeletal myotubes. J. Nutr. Sci. Vitaminol. 2015, 61, 188-194. [CrossRef]

51. HEDYA, S.; HAWILA, N.; ABDIN, A. Luteolin Attenuates Dexamethasone-Induced Skeletal Muscle Atrophy in Male Albino Rats. Med J. Cairo Univ. 2019, 87, 3365-3374.

52. Kim, Y.-J.; Kim, S.-E.; Lee, H.S.; Hong, S.-Y.; Kim, S.-E.; Kim, Y.J.; Lee, J.H.; Park, S.J.; Kim, J.H.; Park, Y.-J. Comparison of linarin content and biological activity in ethanol extraction of Chrysanthemum zawadskii. J. Korean Soc. Food Sci. Nutr. 2016, 45, 1414-1421. [CrossRef]

53. Hyun, M.-R.; Lee, Y.-S.; Park, Y.-H. Antioxidative activity and flavonoid content of Chrysanthemum zawadskii flowers. Hortic. Sci. Technol. 2011, 29, 68-73.

54. Huynh, F.K.; Green, M.F.; Koves, T.R.; Hirschey, M.D. Measurement of fatty acid oxidation rates in animal tissues and cell lines. In Methods in Enzymology; Elsevier: Amsterdam, The Netherlands, 2014; Volume 542, pp. 391-405.

55. Lagouge, M.; Argmann, C.; Gerhart-Hines, Z.; Meziane, H.; Lerin, C.; Daussin, F.; Messadeq, N.; Milne, J.; Lambert, P.; Elliott, P. Resveratrol improves mitochondrial function and protects against metabolic disease by activating SIRT1 and PGC-1 $\alpha$. Cell 2006, 127, 1109-1122. [CrossRef] 